sage, but a method that will not serve us in regard to such questions as whether water will wet us or fire burn us, can hardly be called infallible. But even in regard to questions that must always remain matters of opinion it is not true in the unqualified sense in which Professor James puts it. Probably many men, brought up in the belief that it was their duty to observe the first day of the week by religious worship because the Hebrews were required to abstain from labor on the seventh day, have come to modify their belief without any material change in their practice, and even the belief in regard to the nature and attributes of God may be affected in advance of a change in the conduct based upon it.

The law of association in this regard is subject to the same limitations as we have already found to hold in respect to other matters. Associations of action with belief have a tendency to strengthen it, but, as in the case of emotion, they may be overcome by other considerations, and it is entirely possible for a man to go on for the better part of a lifetime in punctilious conformity to usages which in his heart he despises, and break ont in open rebellion at last. From the ethical point of view, the advice which seems to be implied, of deliberately choosing a way of setting doubts at rest which is as efficacious on the side of error as of truth, of vice as of virtue, seems to me, to say the least, of doubtful tendency. We must often act in doubtful cases, and take the risk, amongst others, of thus confirming ourselves in error, but certainly there can be no more solemn motive for weighing well our beliefs before committing ourselves to them by action than the fact that we may, by habit, pervert our moral sense, blind our judgment and stifle our conscience.

To the man who believes that there is a universe, of which he forms an infinitesimal part, and that all his interests depend on his attitude toward the power that works in it, it is of infinitely more interest to know how he can know the truth than how he can convince himself of this or that. Shall truth be our master, to be followed and obeyed, though he command us to give up all else that we hold dear, or our servant, to be employed as suits our passion or caprice, and dismissed when he will no longer serve our purpose?

This is perhaps the most momentous question that we are called on to decide. The man who makes the wrong choice may or may not attain what he seeks, but though he gain the whole world, he will lose his own soul.

W. L. WORCESTER.

\title{
THE NATURE OF MIND AND THE MEANING OF REALITY.*
}

Professor William James's supposition of "an hallucinatory candle" seen by a "new born mind entirely blank and waiting for experience to begin" is an impossible and self-contradictory figment. We might as well speak of the dry Niagara falls empleyed in the manufacture of some material goods out of nothing. For, first,

* This article was suggested by Dr. W. L. Worcester's criticism on Professor James's Psychology. When Dr. Worcester discusses Proftssor James's supposition of an hallucination in a 
a mind entirely blank is no mind and, secondly, a blank mind if it could exist at all, would have no hallucinations. An hallucinatory candle can be produced only out of the memories or the combination of memories of former candle-sensations. A blind man sees in his dream no colors, and a deaf man hears no symphonies.

A new-born babe is already in possession of many inherited memories. Thus the first sense-impressions after the babe's birth find the organism, especially its skin, nerves and muscles predisposed for their reception. The babe's organism accordingly presents an instance of a relative but not of an absolute blank; an absolute blank of a something that is to develop into mind can mean only a lump of sentient matter at the moment of formation. As soon as it is formed it is exposed in every second of its existence to innumerable impressions which fill the blank with contents and these contents are the mind that is developing.

Sentient substance is not at rest, but like a flame it is possessed of an incessant activity. The form of this activity is both extraordinarily plastic and stable. It is plastic, for every impression together with the reaction of the impression modifies it and leaves a trace: it is stable for the traces of all the impressions and reactions are preserved.

The first sense-impression of a lump of sentient substance produces an irritation which objectively considered is a commotion of the sentient substance and subjectively considered a feeling, the substance being sentient ex hypothesi. This first and primitive feeling is meaningless, for it has not, and cannot have, any reference to any other feeling, memory or mind, and meaning is created through the interaction of feelings with memories of feelings.

Some later sense-impression of the same kind will not only produce the same irritation but also serve as an irritation to awaken the memory-trace left by the former sense-impression. The new feeling will melt into one with the reawakened memory of the former feeling. In the long run many traces of the same kind which are, as it were, deposited in the same place will constitute an organ predisposed to receive the correspondent impressions; and now a sense-impression received by such an organ may be called a sensation. A sensation is not merely a feeling, it is a feeling of a special kind and it is felt to be of a special kind. In other words, a sensation is a feeling that has acquired meaning; and this meaning is the product of the interaction and coöperation of feelings and memories. Sensations have become symbols representing the cause of the sense-impression which produced the sensation, and ideas are symbols of a higher order representing either whole classes of a certain kind of causes of sense-impressions or certain features thereof, or certain relations among them.

blank mind, saying that it would be "the only possible reality of that mind," he almost seems to adopt Professor James's views of the subject himself. Clearness about such fundamental terms as mind and reality, are so much needed that the following remarks may not be out of place as a further explanation of the subject. Exactness in fundamental and general terms will save much labor in detail work. 
Thus every mind is a system of sentient symbols. These symbols being as it were pictures intended somehow to represent or allegorically speaking to portray things are called "ideas," while the things symbolised are in their totality called objective existence or "reality."

Considering the nature of mind, it is obvious that there cannot be an entirely blank mind. We might as well speak of an entirely blank picture. But an entirely blank picture is a canvas and no picture at all. That a mind which is not as yet a mind can have neither sensations nor hallucinations is almost self-evident. Similarly there is no sense in saying that a picture that consists of an utter blank and thus is properly speaking no picture at all but an empty canvas, either does or does not correctly represent a certain object.

The word "real" is used in two senses ( $I$ ) as a name for everything that exists and (2) to signify that kind of existence which is the object of our sensory and mental experience, i. e. the objective world so-called. The former of these two definitions is more comprehensive ; for it includes the realm of mentality, the ideal world of subjectivity. The latter is used in contrast to the subjective world of mental life and thus expressly excludes the ideal realm of the mind and of mental symbols.

The questions as to What is reality? and Is there anything real at all? must not be formulated as they are by Professor James, in terms of belief but in a statement of facts and by defining certain facts as real.

An hallucination is real in the first sense of the word; it is an actual existence; it is a feeling taking place in the mind of some organism. It is also real in the second sense of the word in so far as it is a vibration of a brain structure. However an hallucination is not real in the second sense of the word in so far as its meaning has not its correspondent analogue.

Let the meaning of a certain mental symbol be a candle, under which name we comprise a certain group of experiences, and let the cerebral structure of this mental symbol be awakened by another stimulus than that which is generally called a candle. Those experiences which as a group are called a candle are of a certain kind. If a piece of paper approaches the lighted candle, it will burn. An hallucinatory candle will leave the paper intact, although the person who has the hallucination may see the paper burn. Thus the ideas or images of objects are built up of experiences which have taught us that under certain conditions certain events happen; in consequence of certain actions there are constantly certain reactions taking place. Reality consists of such facts; it is the sum total of all reactions; reality is the nature of objects which react somehow.

Those who jump at the conclusion that our subjective sensations, such as colors, tastes, sounds, etc., must be regarded as objective properties of things, are grossly mistaken. Our sensations are not qualities of things but subjective phenomena; they do not inform us about the nature of things, but reveal to us how things affect our senses. Those however who deny or doubt objective existence are no less 
mistaken. The world is not a subjective phenomenon of sensations, but an objective existence symbolised in sensations.

The question is not "Does reality exist ?" but "What is Reality?" or "What is the meaning of "real'?" When we say "Objects are real," we mean that they resist, they react, their presence produces somehow some effect. When we say, We ourselves are real, we mean that we react upon the objects with which we come in contact, we mean, that in our bodily existence we are objects in an objective world.

Actions and reactions are taking place. This is a fact. He who denies it is like the man who declares that he is not at home; he contradicts himself : for the denial of a question is a reaction upon an action. The term reality is the symbol of the nature of actions and reactions in their efficacy, it denotes the essence of facts and thus the question "Does reality exist?" has no sense. We denote that which exists, that which acts and reacts, that which is a fact, or howsoever we may express it, by the word "reality." We might deny that the reactions of the objective world are constant, or that a certain idea of a certain reaction is erroneous, viz. that the reaction if put to the test would prove to be different from what it was expected-but all these denials and doubts which are of daily occurrence in the domain of science presuppose that there are reactions taking place and reality or objective existence is only a collective name for these reactions and their nature. The name object still preserves the idea of reaction, for object is that which reacts upon touch, which resists, which is objected.

We shall lose ourselves in inextricable confusion by making a matter of doubt and belief what is really a statement of facts. To speak of a doubt or belief in the reality of things in general is tantamount to speaking of a belief in our experiences which, whatever their particular nature may be, are facts. And to doubt our experiences, not the correctness of a particular experience, but experience in general, i. e. the very existence of experience is tantamount to doubting our own being.

A consideration of what we mean by an hallucination can best make clear what we mean, and rationally can only mean, by reality. A real candle is a mental symbol of something which will under certain conditions react in a certain way. An hallucinatory candle is also a mental symbol, but the thing which it purports to mean, does not exist; $i$. e. there is nothing that will react. The symbol is there. but not that something the existence of which the symbol of the idea "candle" would indicate.

This method of dealing with the problem of the old naive realism and the pseudo-critical idealism of former times is not based upon the assumption of the reality of things (which means, of the reality of reality); it is simply a careful formulation of the problem to prevent our being entangled all about with contradictions ; it is the method of rendering clear the basic principle of positivism, that all knowledge is a description of facts, which description of facts is made for the purpose of, dealing with facts.

p. C. 